\begin{tabular}{|l|l|}
\hline Postprint Version & 1.0 \\
\hline Journal website & http://www.jclinepi.com/article/S0895-4356(10)00261-1/abstract \\
\hline Pubmed link & http://www.ncbi.nlm.nih.gov/pubmed/21074969 \\
\hline DOI & $10.1016 /$ j.jclinepi.2010.07.005 \\
\hline
\end{tabular}

This is a NIVEL certified Post Print, more info at http://www.nivel.eu

\title{
Variability in measuring (instrumental) activities of daily living functioning and functional decline in hospitalized older medical patients: a systematic review
}

Bianca M. BuURmana,, BARbara C. van MunsteRa,b, JoHANnA C. KoreVAarb, RoB J. DE HAANc, SOPHIA E. DE ROOIJa

${ }^{a}$ Department of Internal Medicine and Geriatrics, Academic Medical Centre, University of Amsterdam, Amsterdam, The

${ }^{\mathrm{b}}$ Department of Clinical Epidemiology, Biostatistics and Bioinformatics, Academic Medical Centre, University of Amsterdam,

${ }^{c}$ Clinical Research Unit, Academic Medical Centre, University of Amsterdam, The Netherlands

\begin{abstract}
.
Objective: To study instruments used and definitions applied in order to measure (instrumental) activities of daily living (I [ADL]) functioning and functional decline in hospitalized older medical patients.

Study Design: We systematically searched Medline, Embase, and the Cochrane Database of Systematic Reviews from 1990 to January 2010. Articles were included if they (1) focused on acute hospitalization for medical illness in older patients; (2) described the instrument used to measure functioning; and (3) outlined the clinical definition of functional decline. Two reviewers independently extracted data.

Results: In total, 28 studies were included in this review. Five different instruments were used to measure functioning: the Katz ADL index, the IADL scale of Lawton and Brody, the Barthel index, Functional Independence Measure, and Care Needs Assessment. Item content and scoring between and within the instruments varied widely. The minimal amount for decline, as defined by the authors, referred to a decrease in functioning between $2.4 \%$ and $20.0 \%$.

Conclusion: This review shows there is a large variability in measuring (I)ADL functioning of older hospitalized patients and a large range of clinical definitions of functional decline. These conceptual and clinimetric barriers hamper the interpretation and comparison of functional outcome data of epidemiological and clinical studies.
\end{abstract}

\section{WHAT IS NEW?}

Key finding

-There is some conceptual uniformity in measuring functioning of patients in terms of activities of daily living (ADL) but far less uniformity in the operationalization of functional decline.

- A decline of 1 point in one study is equivalent to a 2\% decrease in ADL functioning, whereas in other studies a decline of 1 point is equal to a $20 \%$ decrease in ADL functioning.

What this adds to what was known

- Functional decline is an often-used outcome measure in older patients. 
Buurman, B.M., Munster, B.C. van, Korevaar, J.C., Haan, R.J. de, Rooij, S.E. de. Variability in measuring (instrumental) activities of daily living functioning and functional decline in hospitalized older medical patients: a systematic review. Journal of Clinical Epidemiology: 2011, 64(6), 619-627

- Of all studies measuring ADL functioning, only four of 28 used the complete original content of the measurement instrument.

- Functioning of instrumental activities of daily living was almost never incorporated when operationalizing functional decline.

- There is a strong need for standardization of measurement of functioning.

What is the implication; what should change now

- An expert group should answer several conceptual barriers to achieve uniformity in the process of measurement and operationalization: (1) which activities of daily functioning should be incorporated in the disability continuum; (2) which psychometrically sound instrument(s) should be used to measure the functioning of patients; (3) what should be the optimal time frame in which functional decline is assessed; (4) which clinical and scale scoreerelated statistical definition of functional decline should be used, according to both the medical and patient perspectives.

\section{INTRODUCTION.}

Acute hospitalization in older patients is not without risk because these patients are more prone to adverse events as compared with younger patients [1,2]. An important negative health outcome in this population is functional decline.

Functional decline can lead to (permanent) disability and may lead to a prolonged hospital stay, institutionalization, and even death [3e5]. Medical patients are a vulnerable group for functional decline. They often present to the hospital with deterioration in functioning, as a result of an acute exacerbation of chronic multimorbid conditions.

Not only in daily practice but also in clinical research, functional decline has become a key outcome after hospitalization in older patients, supported by the working group on functional outcome measures in clinical trails [6]. Activities of daily living (ADL) and instrumental activities of daily living (IADL) are an essential part of patients' functional status, as is also demonstrated in the International Classification of Functioning from the World Health Organization (WHO) [7]. ADL and IADL functioning are located centrally in this model and affected by disease, impairment, personal factors, and environmental factors.

Many studies focus on functional decline after acute hospitalization in older patients. A review of McCusker et al. [8] already pointed out that there is a large variability in studies on functional decline in terms of study design, analysis, and time of follow-up. In this article, however, relatively little attention has been given to the measurement itself and the applied definitions of functional decline. Uniformity in measuring functional decline is essential for appraising study results and conducting meta-analyses. To achieve this uniformity, researchers should use reliable and valid instruments with clinically comparable item contents.

Moreover, it is essential that there be agreement between what level of deterioration should be defined as "decline", and at what time point this should be assessed.

The objective of this systematic review was to study the instruments used to measure (I)ADL functioning and functional decline in acutely hospitalized older medical patients.

\section{METHODS}

\subsection{Search strategy}

We conducted a systematic literature search from 1990 to January 2010 in Medline, Embase, and the Cochrane Database of Systematic Reviews (CDSR) to identify English articles on older hospitalized medical patients and functional decline. The following search terms were entered as independent terms, text words, or MESH terms and later combined with the Boolean term "and"': (1) older patient or aged or elderly or senior; (2) acute hospitalization or medical illness or internal disease; and (3) functional decline or functional recovery or loss of independence or functioning or activities of daily living or disability or functional status. Additionally, hand searches of reference lists of selected articles for this review were conducted to identify other relevant articles. The search strategy was performed by one of the authors (B.B.).

2.2. Study selection Articles were included if they (1) focused on acute hospitalization for medical illness, (2) described which instrument was used to measure patients' functioning, and (3) outlined the clinical 
definition of functional decline. For this third point, articles had to describe two time points to measure functioning and had to indicate when a loss of function was defined as decline. All research designs were accepted except for case studies. As the main purpose of this review was to study the instruments used to measure functioning and the applied clinical definitions, we included all studies that reported on these topics, even if a study group published more than once on the same topic.

Studies that reported on a specific medical condition or diagnosis were excluded. For example, if an article solely focused on COPD and functioning, this was an exclusion criterion because many disease-specific functional measurement instruments exist that cannot be applied to a general population of acutely hospitalized older patients.

Studies that reported on patients aged less than 60 years were excluded as well. Studies conducted on geriatric ward were only included if most patients were admitted for acute medical illness.

\subsection{Data extraction}

Data were independently abstracted by two investigators (B.B. and B.M.) in terms of study characteristics (patients' age, study group size, study setting, and design) and properties of the measures used (type of instrument, item content, scoring procedure [patient, proxy, or professional], scaling of the items, and score range). Additionally, we registered the time points of assessments and the (statistical) definition of functional decline applied. Baseline assessments were defined as premorbid in case the scoring referred to the situation 2 weeks or more before hospital admission and were scored as at admission if the assessment took place at admission.

Disagreements in the abstracting of the data were solved by discussion. If a consensus could not be reached, the final decision was made by a third reviewer (J.K.).

We intended to conduct a purely descriptive review on measurements and, therefore, did not screen the articles on study quality in itself.

\subsection{Statistical analysis}

Study characteristics and properties of the measures were summarized using simple descriptive statistics. To compare the definition of functional decline applied in the different studies, minimal amount for decline as defined in the article was expressed in percentage change. Therefore, if an original range of scores was from 0 to 5 and the minimal amount for decline as indicated by the authors was 1 point, a patient “declined”' $20 \%$ of his ADL capacities.

\section{RESULTS}

\subsection{Search results}

Combining all search terms resulted in 397 articles, of which 68 were eligible for the review based on title and abstract (Fig. 1). Main reasons for initial exclusion were the following: functional decline or recovery was not the outcome measure; article did not concern acutely hospitalized medical patients; or studies that focused on specific diseases.

A manual search of the reference lists of selected articles resulted in an additional 10 studies.

The 78 studies that initially met the inclusion criteria were completely reviewed by the two reviewers. Of these studies, 20 were additionally excluded because they had other outcomes (e.g., nursing home admission, functional status rather than decline or recovery, mortality), 11 studies did not describe the measurement instrument used or did not yield a definition of functional decline or recovery, 13 studies were in other populations (community-dwelling elderly, and patients from the Emergency Department), two studies reported on functioning at a certain time point and not compared functioning between two time points, and four studies focused solely on the psychometric properties of instruments. Finally, 28 articles were included for analysis. (Reference list of the complete search strategy is available on request.) 3.2. Characteristics of the studies

Table 1 presents the main characteristics of the included studies. There were three randomized clinical trials [9e11] and one nonrandomized clinical trial [12], and all other studies were prospective cohort studies [4,13e35]. A total of 23 studies were conducted on medical wards [4,9e12,14,15,17,19e27,29e33,35], three studies on combined medical and geriatric wards [4,13,28], and two studies on geriatric wards [16,34]. The number of included patients varied from 45 to 5,675 patients, and weighted mean age across the studies was 78.4 years (range $73 e 84$ years) and percentage of included women was $57.2 \%$. 
Buurman, B.M., Munster, B.C. van, Korevaar, J.C., Haan, R.J. de, Rooij, S.E. de. Variability in measuring (instrumental) activities of daily living functioning and functional decline in hospitalized older medical patients: a systematic review. Journal of Clinical Epidemiology: 2011, 64(6), 619-627

All studies focused on (I)ADL functioning of patients.

Twenty of 28 studies use premorbid functioning as the baseline measurement in defining change over time [4,9,11e14,16e18,20,21,24e27,29e31,34,35]. Although most studies used more than one endpoint for decline, ADL function during hospital admission or at hospital discharge was identified as the primary endpoint in 20 studies [4,9,10,14e16,19e25,27,28,30,31,33,34]; the remaining eight studies used 2 weeks after admission to a 6-month period after discharge [11e13,17,18,26,29,32,35].

In 17 studies, the instruments were scored by patients or by proxies for patients with cognitive impairment $[4,9 \mathrm{e} 14,18 \mathrm{e} 20,22,28,30 \mathrm{e} 34]$. In seven studies, the instruments were scored by professionals [15e17,21,23e25]. In the remaining studies, the instruments were filled in by either the patient or the proxy $[26,27,29,35]$.

\section{[FIGURE 1]}

\section{[TABLE 1]}

\subsection{Instruments used to measure functioning}

We identified five different instruments, which were used to measure the functioning of patients (Table 1): The Katz ADL index (22 studies) [9e12,14,15,17e20,22e33], Barthel index (three studies) [4,13,34], Care Needs Assessment (CNA; one study) [21], and Functional Independence Measure (FIM; two studies) $[16,35]$. Four studies that used the Katz ADL index also measured IADL by Lawton and Brody and used the combination of ADL and IADL in the definition of functional decline [11,30,32,33]. Most other studies did measure IADL functioning, but this type of functioning was not included in the definition of functional decline. See Table 2 for a short description of measurement instruments included in this review.

\section{[TABLE 2]}

\subsection{Content of the instruments}

The fourth column of Table 3 shows the content of the identified scales. Only one of the 22 studies that referred to the original Katz ADL scale actually used the complete original content of this scale [25]. Four studies that also assessed IADL as part of functional decline measured this concept according to the original content of the scale $[11,30,32,33]$. This was also true for the three studies that used the Barthel index $[4,13,34]$. For the only study that used the CNA, judgment of the original content was not relevant because this instrument was developed in this study [21]. Both studies that applied the FIM did not use the original items completely $[16,35]$.

Table 4 shows the items of the different versions of the Katz ADL index as was used in the 22 studies [9e12,14,15,17e20,22e33]. The original content of the scale is highlighted in gray. The item content varied widely between studies, although some items were measured in all studies. Based on the original content, $100 \%$ uniformity was found on the items dressing, bathing, eating, and toileting [9e12,14,15,17e20,22e33]. Transferring from bed to chair was measured in $82 \%$ of the studies [9e12,14,17,19,20,22,25e29,31e33,36] and incontinence in $14 \%$ of the studies $[18,19,25]$.

\subsection{Definition of functional decline}

The minimal amount of decline, as defined in the different studies, varied between $2.4 \%$ and $20 \%$ (Table 3, last two columns).

In studies where functioning was measured with the Katz ADL index, the minimal amount of decline referred to a decrease in the level of functioning between $3.6 \%$ and $20 \%$ [9,10,12,14,15,17e20,22e29,31]. In studies that also incorporated IADL functioning, the minimal decline referred to a decrease between $5.9 \%$ and $8.3 \%[11,30,32,33]$.

Two studies with the Barthel index used the same definition of a minimal amount of decline $(10 \%)[4,13]$, and one study only described return to baseline functioning [34]. In the two studies using the FIM, the minimal level of decline ranged from $2.4 \%$ to $7.7 \%$ [16,35]. In the study with the CNA, decline was not defined with a cutoff score measure but as a restoration to baseline functioning [21]. 


\section{[TABLE 3]}

\section{Discussion}

This systematic review showed that there is, to some extent, conceptual uniformity in measuring functioning of patients in terms of ADL but far less uniformity in the operationalization of this concept and the definition of functional decline. Only three of 28 studies applied the complete original content of the instrument they referred to, whereas the cutoff scores reflecting functional decline ranged from about $2 \%$ to $20 \%$ of the instruments' total score range.

This review stresses a strong need for standardization in measuring functioning of hospitalized older medical patients and the use of clinical definitions of functional decline. As long as no consensus is reached regarding this subject, it would be difficult or even impossible to compare research outcomes of studies reporting the incidence of functional decline and its predictors or to perform systematic reviews and metaanalyses. This finding adds to the conclusion of an earlier review regarding predictors of functional decline [8]. In the road to standardization in measuring functioning, several questions need to be answered.

One of the first questions is how broad the disability continuum should be defined. The International Classification of Functioning, disability and health, published by the WHO, provides an internationally adapted framework on functioning of patients. He'bert [37] already discussed the importance of this theoretical framework in relation to the functional decline syndrome. In our review, almost all articles on functional decline, however, have operationalized functional decline solely in terms of ADL functioning of patients. Some researchers extend this continuum by also measuring patients' ability to perform complex activities in terms of IADL, but only few did include this type of activity in their definition of functional decline.

The Katz ADL index instrument was applied in the vast majority of the studies included in our review. However, there was a substantial difference between the studies with regard to the encompassed scale items and scoring. Bathing, dressing, toileting, eating, and, to some extent, transfer turned out to be the core of the instruments, but this was less true for the assessment of incontinence.

Some studies did not incorporate incontinence in the Katz because of the low reliability when asked in selfreports.

However, both in the original version [38] and the modified version [39], incontinence was included when validating the index. Inouye et al. [40] suggested that the presence of geriatric syndromes, such as incontinence, reveal the frailty or vulnerability of a patient. In the clinical setting, measuring the presence of incontinence might bring up some difficulties because part of the patients get an indwelling urinary catheter at the time of hospital admission.

This could be resolved by consensus on how to handle this question at the time of hospital admission.

An important feature is the reliability, validity, and responsiveness of the measurement instruments based on summated total scores. This issue is amplified by the ordinal nature of summated scores, meaning that a given difference in scores at one point on the scale does not necessarily represent the same amount of functional change as an identical difference at another point on the scale. Modern clinimetric methods based on item response theory (IRT) can overcome this. The advantage of this approach is that not all items of an instrument have to be assessed in all patients to determine their level of functioning. This allows the user to obtain a sufficiently detailed clinical picture using a small number of items. It not only leads to more efficient data collection but the scores of different subgroups are comparable because the difficulty of each item has been estimated beforehand. Two examples of scales that use IRT are the Amsterdam Linear Disability scale and interRAI Acute Care instrument [41,42]. Although the interest in the use of this promising measurement paradigm has grown and IRT is gaining acceptance in various fields of medical research [43,44], IRT is not yet been widespread implemented in patient care and clinical outcome research.

We also aimed to study the clinical definitions of functional decline used in studies among older hospitalized medical patients. Twenty of 28 studies used premorbid functioning as the starting point to measure functional decline. One important argument to focus on premorbid functioning as starting point is that there is evidence that many acutely hospitalized patients declined in the short period before hospital admission $[16,20]$. A major purpose of interventions should be to bring patients back to their initial premorbid level of functioning. 
Buurman, B.M., Munster, B.C. van, Korevaar, J.C., Haan, R.J. de, Rooij, S.E. de. Variability in measuring (instrumental) activities of daily living functioning and functional decline in hospitalized older medical patients: a systematic review. Journal of Clinical Epidemiology: 2011, 64(6), 619-627

Most studies selected functioning at hospital discharge as the endpoint of interest. However, one can challenge the rational of this time point. A study in communitydwelling older patients demonstrated that the process of functional decline and recovery is a dynamic process. Gill et al. [45] measured ADL functioning of patients monthly and showed that up to 6 months after patients declined in functioning, they were able to recover but were also more vulnerable to decline again after 6 months. This might suggest that after hospital discharge, patients have the capacity to further recover. More studies on this process are needed, also to discuss if an appropriate time point for the measurement of functional decline can be identified. This might also depend on patient group, treatment, and rehabilitation goals.

Next to the definition of the appropriate time frame in which functional decline is measured, more discussion is needed regarding the optimal scale cutoff scores used to define decline. We demonstrated that a minimal decline score as applied in different studies varied substantially. The question remains when we should speak of a clinical relevant decline in functioning. This could be defined objectively, by deciding clinical relevant decline is if a patient declines for example $5 \%$ of its actual functioning, or $20 \%$. And should this deterioration be measured in absolute scoring terms or in relative terms by incorporating patient's initial level of functioning? Additionally, the patient perspective on functional decline has not been described frequently, which hampers a well-balanced definition of clinical relevant decline.

Winograd et al. [46] reported that patients' self-report of functioning is an essential predictor of actual decline 12 months after hospitalization. Further studies on this topic are lacking.

In summary, our review showed that there is a large variability in measuring (I)ADL functioning of older hospitalized medical patients and a large range of clinical definitions of functional decline. These conceptual and clinimetric barriers hamper the interpretation and comparison of functional outcome data of epidemiological and clinical studies. In view of the range of complex methodological questions to be answered on the road to standardization of measuring functioning of older (hospitalized) patients, we propose that a task force with key informants will pick up these questions. This could, for example, be done by the Working Group on Functional Outcomes because ADL functioning forms an important part of patients' functional status.

Furthermore, focus group discussions with patients could give important additional information regarding the patients' perspective on how they appraise functional decline and the acceptable boundaries.

The agenda of this task force should at least consist of the following topics; (1) which activities of daily functioning should be incorporated in the disability continuum, (2) which psychometrically sound instrument(s) should be used to measure the functioning of patients, (3) what should be the optimal time frame in which functional decline is assessed, and (4) which clinical and scale scoreerelated statistical definition of functional decline should be used, according to both the medical and patient perspective.

Pending the answers on these questions, we advice to measure disability with the complete version of the validated Katz ADL index score.

\section{REFERENCES}

[1] Baker GR, Norton PG, Flintoft V, Blais R, Brown A, Cox J, et al. The Canadian Adverse Events Study: the incidence of adverse events among hospital patients in Canada. CMAJ 2004;170:1678e86.

[2] Creditor MC. Hazards of hospitalization of the elderly. Ann Intern Med 1993;118:219e23.

[3] Alarcon T, Barcena A, Gonzalez-Montalvo JI, Penalosa C, Salgado A. Factors predictive of outcome on admission to an acute geriatric ward. Age Ageing 1999;28:429e32.

[4] Jarrett PG, Rockwood K, Carver D, Stolee P, Cosway S. Illness presentation in elderly patients. Arch Intern Med 1995;155:1060e4.

[5] Miller EA, Weissert WG. Predicting elderly people's risk for nursing home placement, hospitalization, functional impairment, and mortality: a synthesis. Med Care Res Rev 2000;57(3):259e97.

[6] Working Group on Functional Outcome Measures in Clinical Trials.

Functional outcomes for clinical trials in frail older persons: time to be moving. J Gerontol A Biol Sci Med Sci 2008;63(2):160e4.

[7] World Health Organisation. International classification of functioning.

Geneva, Switzerland: World Health Organisation; 2001.

[8] McCusker J, Kakuma R, Abrahamowicz M. Predictors of functional decline in hospitalized elderly patients: a systematic review. J Gerontol A Biol Sci Med Sci 2002;57:M569e77.

[9] Counsell SR, Holder CM, Liebenauer LL, Palmer RM, Fortinsky RH, Kresevic DM, et al. Effects of a multicomponent intervention on functional outcomes and process of care in hospitalized older patients: a 
Buurman, B.M., Munster, B.C. van, Korevaar, J.C., Haan, R.J. de, Rooij, S.E. de. Variability in measuring (instrumental) activities of daily living functioning and functional decline in hospitalized older medical patients: a systematic review. Journal of Clinical Epidemiology: 2011, 64(6), 619-627

randomized controlled trial of Acute Care for Elders (ACE) in a community hospital. J Am Geriatr Soc 2000;48:1572e81.

[10] Landefeld CS, Palmer RM, Kresevic DM, Fortinsky RH, Kowal J. A randomized trial of care in a hospital medical unit especially designed to improve the functional outcomes of acutely ill older patients.

N Engl J Med 1995;332:1338e44.

[11] Mahoney JE, Sager MA, Jalaluddin M. Use of an ambulation assistive device predicts functional decline associated with hospitalization.

J Gerontol A Biol Sci Med Sci 1999;54(2):M83e8.

[12] Leff B, Burton L, Mader SL, Naughton B, Burl J, Greenough WB III, et al. Comparison of functional outcomes associated with hospital at home care and traditional acute hospital care. J Am Geriatr Soc 2009;57(2):273e8.

[13] Andrew MK, Freter SH, Rockwood K. Incomplete functional recovery after delirium in elderly people: a prospective cohort study. BMC Geriatr 2005;5:5.

[14] Boyd CM, Landefeld CS, Counsell SR, Palmer RM, Fortinsky RH, Kresevic D, et al. Recovery of activities of daily living in older adults after hospitalization for acute medical illness. J Am Geriatr Soc 2008;56:2171e9.

[15] Brown CJ, Friedkin RJ, Inouye SK. Prevalence and outcomes of low mobility in hospitalized older patients. J Am Geriatr Soc 2004;52: 1263e70.

[16] Carlson JE, Zocchi KA, Bettencourt DM, Gambrel ML, Freeman JL, Zhang D, et al. Measuring frailty in the hospitalized elderly: concept of functional homeostasis. Am J Phys Med Rehabil 1998;77:252e7.

[17] Chaudhry SI, Friedkin RJ, Horwitz RI, Inouye SK. Educational disadvantage impairs functional recovery after hospitalization in older persons. Am J Med 2004;117:650e6.

[18] Cornette P, Swine C, Malhomme B, Gillet JB, Meert P, D'Hoore W.

Early evaluation of the risk of functional decline following hospitalization of older patients: development of a predictive tool. Eur J Public Health 2006;16:203e8.

[19] Corsonello A, Pedone C, Lattanzio F, Lucchetti M, Garasto S, Di MM, et al. Potentially inappropriate medications and functional decline in elderly hospitalized patients. J Am Geriatr Soc 2009;57: 1007e14.

[20] Covinsky KE, Palmer RM, Fortinsky RH, Counsell SR, Stewart AL, Kresevic D, et al. Loss of independence in activities of daily living in older adults hospitalized with medical illnesses: increased vulnerability with age. J Am Geriatr Soc 2003;51:451e8.

[21] Hirsch CH, Sommers L, Olsen A, Mullen L, Winograd CH. The natural history of functional morbidity in hospitalized older patients. J Am Geriatr Soc 1990;38:1296e303.

[22] Holroyd-Leduc JM, Sen S, Bertenthal D, Sands LP, Palmer RM, Kresevic DM, et al. The relationship of indwelling urinary catheters to death, length of hospital stay, functional decline, and nursing home admission in hospitalized older medical patients. J Am Geriatr Soc 2007;55(2):227e33.

[23] Inouye SK, Wagner DR, Acampora D, Horwitz RI, Cooney LM Jr, Hurst LD, et al. A predictive index for functional decline in hospitalized elderly medical patients. J Gen Intern Med 1993;8:645e52.

[24] Inouye SK, Wagner DR, Acampora D, Horwitz RI, Cooney LM Jr, Tinetii ME. A controlled trial of a nursing-centered intervention in hospitalized elderly medical patients: the Yale Geriatric Care Program.

J Am Geriatr Soc 1993;41:1353e60.

[25] Inouye SK, Rushing JT, Foreman MD, Palmer RM, Pompei P. Does delirium contribute to poor hospital outcomes? A three-site epidemiologic study. J Gen Intern Med 1998;13(4):234e42.

[26] Lang PO, Meyer N, Heitz D, Drame M, Jovenin N, Ankri J, et al.

Loss of independence in Katz's ADL ability in connection with an acute hospitalization: early clinical markers in French older people.

Eur J Epidemiol 2007;22:621e30.

[27] Lindenberger EC, Landefeld CS, Sands LP, Counsell SR, Fortinsky RH, Palmer RM, et al. Unsteadiness reported by older hospitalized patients predicts functional decline. J Am Geriatr Soc 2003;51:621e6.

[28] Maraldi C, Volpato S, Cesari M, Cavalieri M, Onder G, Mangani I, et al. Anemia and recovery from disability in activities of daily living in hospitalized older persons. J Am Geriatr Soc 2006;54:632e6.

[29] Murray AM, Levkoff SE, Wetle TT, Beckett L, Cleary PD, Schor JD, et al. Acute delirium and functional decline in the hospitalized elderly patient. J Gerontol 1993;48(5):M181e6.

[30] Sager MA, Franke T, Inouye SK, Landefeld CS, Morgan TM, Rudberg MA, et al. Functional outcomes of acute medical illness and hospitalization in older persons. Arch Intern Med 1996;156: 645e52.

[31] Sager MA, Rudberg MA, Jalaluddin M, Franke T, Inouye SK, Landefeld CS, et al. Hospital admission risk profile (HARP): identifying older patients at risk for functional decline following acute medical illness and hospitalization. J Am Geriatr Soc 1996;44(3): 251e7. 
Buurman, B.M., Munster, B.C. van, Korevaar, J.C., Haan, R.J. de, Rooij, S.E. de. Variability in measuring (instrumental) activities of daily living functioning and functional decline in hospitalized older medical patients: a systematic review. Journal of Clinical Epidemiology: 2011, 64(6), 619-627

[32] Sands LP, Yaffe K, Covinsky K, Chren MM, Counsell S, Palmer R, et al. Cognitive screening predicts magnitude of functional recovery from admission to 3 months after discharge in hospitalized elders.

J Gerontol A Biol Sci Med Sci 2003;58(1):37e45.

[33] Sands LP, Landefeld CS, Ayers SM, Yaffe K, Palmer R, Fortinsky R, et al. Disparities between black and white patients in functional improvement after hospitalization for an acute illness. J Am Geriatr Soc 2005;53:1811e6.

[34] Sleiman I, Rozzini R, Barbisoni P, Morandi A, Ricci A, Giordano A, et al. Functional trajectories during hospitalization: a prognostic sign for elderly patients. J Gerontol A Biol Sci Med Sci 2009;64: 659e63.

[35] Wakefield BJ, Holman JE. Functional trajectories associated with hospitalization in older adults. West J Nurs Res 2007;29(2):161e77.

[36] Sager MA, Rudberg MA. Functional decline associated with hospitalization for acute illness. Clin Geriatr Med 1998;14:669e79.

[37] He'bert R. Functional decline in old age. CMAJ 1997;157:1037e45.

[38] Katz S, Ford AB, Moskowitz RW, Jackson BA, Jaffe MW. Studies of illness in the aged. The index of ADL: a standardized measure of biological and psychosocial function. JAMA 1963;185:914e9.

[39] Weinberger M, Samsa GP, Schmader K, Greenberg SM, Carr DB, Wildman DS. Comparing proxy and patients' perceptions of patients' functional status: results from an outpatient geriatric clinic. J Am Geriatr Soc 1992;40:585e8.

[40] Inouye SK, Studenski S, Tinetti ME, Kuchel GA. Geriatric syndromes: clinical, research, and policy implications of a core geriatric concept. J Am Geriatr Soc 2007;55:780e91.

[41] Gray LC, Bernabei R, Berg K, Finne-Soveri H, Fries BE, Hirdes JP, et al. Standardizing assessment of elderly people in acute care: the interRAI Acute Care instrument. J Am Geriatr Soc 2008;56:536e41.

[42] Holman R, Weisscher N, Glas CA, Dijkgraaf MG, Vermeulen M, de Haan RJ, et al. The Academic Medical Center Linear Disability Score (ALDS) item bank: item response theory analysis in a mixed patient population. Health Qual Life Outcomes 2005;3:83.

[43] Hays RD, Morales LS, Reise SP. Item response theory and health outcomes measurement in the 21st century. Med Care 2000;38(9 Suppl): II28e42.

[44] McHorney CA. Ten recommendations for advancing patient-centered outcomes measurement for older persons. Ann Intern Med 2003;139 (5 Pt 2):403e9.

[45] Gill TM, Hardy SE, Williams CS. Underestimation of disability in community-living older persons. J Am Geriatr Soc 2002;50:1492e7.

[46] Winograd CH, Lindenberger EC, Chavez CM, Mauricio MP, Shi H, Bloch DA. Identifying hospitalized older patients at varying risk for physical performance decline: a new approach. J Am Geriatr Soc 1997;45:604e9.

[47] Lawton MP, Brody EM. Assessment of older people: self-maintaining and instrumental activities of daily living. Gerontologist 1969;9: 179e86.

[48] Mahoney FI, Barthel DW. Functional evaluation: The BARTHEL Index.

Md State Med J 1965;14:61e5.

[49] Keith RA, Granger CV, Hamilton BB, Sherwin FS. The functional independence measure: a new tool for rehabilitation. Adv Clin Rehabil 1987;1:6e18. 
Buurman, B.M., Munster, B.C. van, Korevaar, J.C., Haan, R.J. de, Rooij, S.E. de. Variability in measuring (instrumental) activities of daily living functioning and functional decline in hospitalized older medical patients: a systematic review. Journal of Clinical Epidemiology: 2011, 64(6), 619-627

\section{[TABLES AND FIGURES]}


Buurman, B.M., Munster, B.C. van, Korevaar, J.C., Haan, R.J. de, Rooij, S.E. de. Variability in measuring (instrumental) activities of daily living functioning and functional decline in hospitalized older medical patients: a systematic review. Journal of Clinical Epidemiology: 2011, 64(6), 619-627

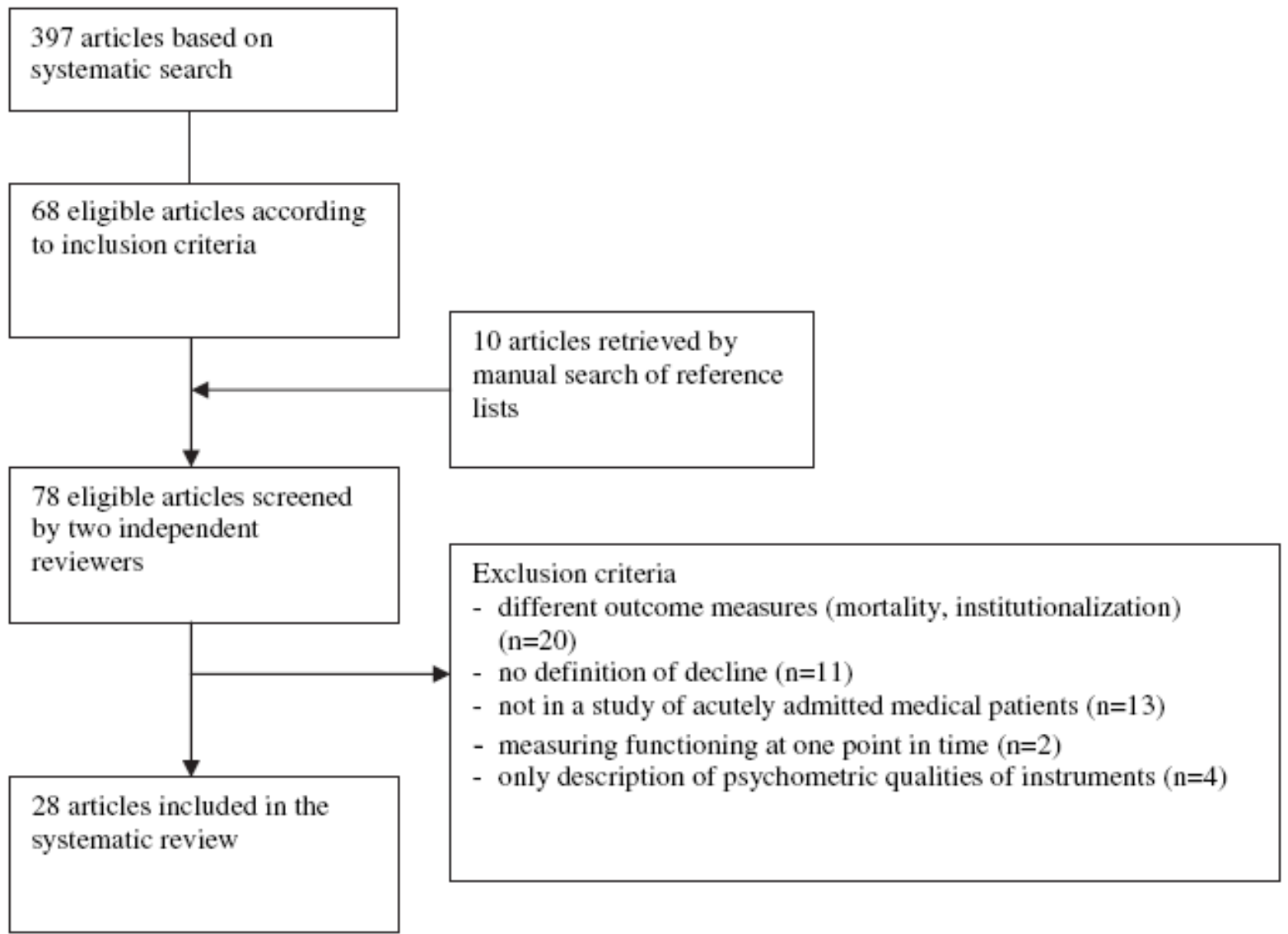

Fig. 1. Flow diagram of search strategy and study selection. 
Buurman, B.M., Munster, B.C. van, Korevaar, J.C., Haan, R.J. de, Rooij, S.E. de. Variability in measuring (instrumental) activities of daily living functioning and functional decline in hospitalized older medical patients: a systematic review. Journal of Clinical Epidemiology: 2011, 64(6), 619-627

Table 1

Main characteristics of the included studies

\begin{tabular}{|c|c|c|c|c|c|c|c|c|c|}
\hline Study no & First author & Year & Setting & No of pts & Mean age & Instrument & $\begin{array}{l}\text { Baseline } \\
\text { functioning }\end{array}$ & $\begin{array}{l}\text { Primary } \\
\text { outcome decline }\end{array}$ & Scored by \\
\hline 1 & Corsonello [19] & 2009 & Medical & 506 & 80 & Katz ADL & Admission & Discharge & Patient or proxy \\
\hline 2 & Leff [12] & 2009 & Medical & 214 & 77 & Katz ADL & Premorbid & 2 wk after admission & Patient or proxy \\
\hline 3 & Inouye [23] & 1993 & Medical & 330 & 78 & Katz ADL & Admission & Discharge & Professional \\
\hline 4 & Brown [15] & 2004 & Medical & 498 & 79 & Katz ADL & Admission & Discharge & Professional \\
\hline 5 & Murray [29] & 1993 & Medical & 325 & 81 & Katz ADL & Premorbid & $3 \mathrm{mo}$ & Proxy \\
\hline 6 & Chaudry [17] & 2004 & Medical & 862 & 80 & Katz ADL & Premorbid & $6 \mathrm{mo}$ & Professional \\
\hline 7 & Sager [31] & 1996 & Medical & 827 & 79 & Katz ADL & Premorbid & Discharge & Patient or proxy \\
\hline 8 & Inouye [24] & 1993 & Medical & 216 & 81 & Katz ADL & Premorbid & Discharge & Professional \\
\hline 9 & Comette [18] & 2005 & $\begin{array}{l}\text { Medical/ } \\
\text { geriatric }\end{array}$ & 550 & 80 & Katz ADL & Premorbid & $3 \mathrm{mo}$ & Patient or proxy \\
\hline 10 & Maraldi [28] & 2006 & $\begin{array}{l}\text { Medical/ } \\
\text { geriatric }\end{array}$ & 5,675 & 81 & Katz ADL & Admission & Discharge & Patient or proxy \\
\hline 11 & Landefeld [10] & 1995 & Medical & 651 & 80 & Katz ADL & Admission & Discharge & Patient or proxy \\
\hline 12 & Inouye [25] & 1998 & Medical & 727 & 79 & Katz ADL & Premorbid & Discharge & Professional \\
\hline 13 & Counsell [9] & 2000 & Medical & 1,531 & 80 & Katz ADL & Premorbid & Discharge & Patient or proxy \\
\hline 14 & Covinsky [20] & 2003 & Medical & 2,293 & 80 & Katz ADL & Premorbid & Discharge & Patient or proxy \\
\hline 15 & Lindenberger [27] & 2003 & Medical & 1,557 & 78 & Katz ADL & Premorbid & Discharge & Patient \\
\hline 16 & Holroyd-leduc [22] & 2007 & Medical & 535 & 82 & Katz ADL & Admission & Discharge & Patient or proxy \\
\hline 17 & Lang [26] & 2007 & Medical & 619 & 83 & Katz ADL & Premorbid & $1 \mathrm{mo}$ & Patient \\
\hline 18 & Boyd [14] & 2008 & Medical & 2,279 & 80 & Katz ADL & Premorbid & Discharge & Patient or proxy \\
\hline 19 & Sands [32] & 2003 & Medical & 193 & 80 & $\begin{array}{l}\text { Katz ADL/IADL } \\
\text { Lawton/mobility }\end{array}$ & Admission & $3 \mathrm{mo}$ & Patient or proxy \\
\hline 20 & Sager [30] & 1996 & Medical & 1,279 & 79 & $\begin{array}{l}\text { Katz ADL/IADL } \\
\text { Lawton }\end{array}$ & Premorbid & Discharge & Patient or proxy \\
\hline 21 & Sands [33] & 2005 & Medical & 2,364 & 80 & $\begin{array}{l}\text { Katz ADL/IADL } \\
\text { Lawton }\end{array}$ & Admission & Discharge & Patient or proxy \\
\hline 22 & Mahoney [11] & 1999 & Medical & 1,212 & 79 & $\begin{array}{l}\text { Katz ADL/IADL } \\
\text { Lawton }\end{array}$ & Premorbid & $3 \mathrm{mo}$ & Patient or proxy \\
\hline 23 & Sleiman [34] & 2009 & Geriatric & 1,119 & 81 & Barthel index & Premorbid & Discharge & Patient or proxy \\
\hline 24 & Jarrett [4] & 1995 & Medical & 193 & 78 & Barthel index & Premorbid & Discharge & Patient or proxy \\
\hline 25 & Andrew [13] & 2005 & $\begin{array}{l}\text { Medical/ } \\
\text { geriatric }\end{array}$ & 77 & 79 & Barthel index & Premorbid & $6 \mathrm{mo}$ & Patient or proxy \\
\hline 26 & Hirsch [21] & 1990 & Medical & 71 & 84 & $\mathrm{CNA}$ & Premorbid & Discharge & Professional \\
\hline 27 & Carlson [16] & 1998 & Geriatric & 122 & 73 & FIM & Premorbid & Discharge & Professional \\
\hline 28 & Wakefield [35] & 2007 & Medical & 45 & 74 & FIM & Premorbid & Day 4 of admission & Patient \\
\hline
\end{tabular}

Abbreviations: ADL, activities of daily living; IADL, instrumental activities of daily living; CNA, Care Needs Assessment; FIM, Functional Independence Measure.

Table 2

Short description of instruments included in the review

\begin{tabular}{lclc}
\hline Instrument & $\begin{array}{l}\text { Number } \\
\text { of items }\end{array}$ & Scaling & $\begin{array}{c}\text { Complete } \\
\text { independence }\end{array}$ \\
\hline Katz ADL index [38] & 6 & Dichotomous & $0-6$ \\
IADL by Lawton and Brody [47] & 8 & Dichotomous & $0-8$ \\
Barthel index [48] & 15 & Likert scale; scaling differs per item & $0-100$ \\
Functional Independence Measure [49] & 18 & Seven-point Likert scale & $18-126$ \\
Care Needs Assessment [21] & 7 & Three-point Likert scale & $0-14$ \\
\hline
\end{tabular}

Abbreviations: ADL, activities of daily living; IADL, instrumental activities of daily living. 
Buurman, B.M., Munster, B.C. van, Korevaar, J.C., Haan, R.J. de, Rooij, S.E. de. Variability in measuring (instrumental) activities of daily living functioning and functional decline in hospitalized older medical patients: a systematic review. Journal of Clinical Epidemiology: 2011, 64(6), 619-627

Table 3

Instrument content and definition of decline of included studies

\begin{tabular}{|c|c|c|c|c|c|c|c|}
\hline Study no & First author & Instrument & $\begin{array}{l}\text { Original } \\
\text { content }\end{array}$ & $\begin{array}{l}\text { Original item } \\
\text { scaling }\end{array}$ & $\begin{array}{l}\text { Range of } \\
\text { total scores }\end{array}$ & $\begin{array}{l}\text { Original cutoff } \\
\text { for decline }\end{array}$ & $\begin{array}{l}\text { Standardized cutoff } \\
\text { for decline }(\%)\end{array}$ \\
\hline 1 & Corsonello [19] & Katz ADL & & & $0-28$ & 1 point & 3.6 \\
\hline 2 & Leff [12] & Katz ADL & & & $0-25$ & 1 point & 4.0 \\
\hline 3 & Inouye [23] & Katz ADL & & & $0-10$ & 1 point & 10.0 \\
\hline 4 & Brown [15] & Katz ADL & & & $0-10$ & 1 point & 10.0 \\
\hline 5 & Murray [29] & Katz ADL & & $\mathrm{x}$ & $0-7$ & 1 point & 14.3 \\
\hline 6 & Chaudry [17] & Katz ADL & & $\mathrm{x}$ & $0-7$ & 1 point & 14.3 \\
\hline 7 & Sager [31] & Katz ADL & & $\mathrm{x}$ & $0-6$ & 1 point & 16.7 \\
\hline 8 & Inouye [24] & Katz ADL & $\mathrm{x}$ & $\mathrm{x}$ & $0-6$ & 1 point & 16.7 \\
\hline 9 & Cornette [18] & Katz ADL & & $\mathrm{x}$ & $0-6$ & 1 point & 16.7 \\
\hline 10 & Maraldi [28] & Katz ADL & & $\mathrm{x}$ & $0-6$ & 1 point & 16.7 \\
\hline 11 & Landefeld [10] & Katz ADL & & $\mathrm{x}$ & $0-5$ & 1 point & 20.0 \\
\hline 12 & Inouye [25] & Katz ADL & & $\mathrm{x}$ & $0-5$ & 1 point & 20.0 \\
\hline 13 & Counsell [9] & Katz ADL & & $\mathrm{x}$ & $0-5$ & 1 point & 20.0 \\
\hline 14 & Covinsky [20] & Katz ADL & & $\mathrm{x}$ & $0-5$ & 1 point & 20.0 \\
\hline 15 & Lindenberger [27] & Katz ADL & & $\mathrm{x}$ & $0-5$ & 1 point & 20.0 \\
\hline 16 & Holroyd-leduc [22] & Katz ADL & & $\mathrm{x}$ & $0-5$ & 1 point & 20.0 \\
\hline 17 & Lang [26] & Katz ADL & & $\mathrm{x}$ & $0-5$ & 1 point & 20.0 \\
\hline 18 & Boyd [14] & Katz ADL & & $\mathrm{x}$ & $0-5$ & 1 point & 20.0 \\
\hline 19 & Sands [32] & Katz ADL/IADL/ mobility & Only IADL & $\mathrm{x}$ & $0-17$ & 1 point & 5.9 \\
\hline 20 & Sager $[30]$ & Katz ADL/IADL & Only IADL & $\mathrm{x}$ & $0-13$ & 1 point & 7.7 \\
\hline 21 & Sands [33] & Katz ADL/IADL & Only IADL & $\mathrm{x}$ & $0-13$ & 1 point & 7.7 \\
\hline 22 & Mahoney [11] & Katz ADL/IADL & Only IADL & $\mathrm{x}$ & $0-12$ & 1 point & 8.3 \\
\hline 23 & Sleiman [34] & Barthel index & $\mathrm{x}$ & $\mathrm{x}$ & $0-100$ & Return to BL score & - \\
\hline 24 & Jarrett [4] & Barthel index & $\mathrm{x}$ & $\mathrm{x}$ & $0-100$ & 10 points & 10.0 \\
\hline 25 & Andrew [13] & Barthel index & $\mathrm{x}$ & $\mathrm{x}$ & $0-100$ & 10 points & 10.0 \\
\hline 26 & Hirsch [21] & $\mathrm{CNA}$ & NA & NA & $0-14$ & Return to BL score & - \\
\hline 27 & Carlson [16] & FIM & & $\mathrm{x}$ & $7-49$ & 1 point & 2.4 \\
\hline 28 & Wakefield [35] & FIM & & & $0-13$ & 1 point & 7.7 \\
\hline
\end{tabular}
applicable; FIM, Functional Independence Measure. 
Buurman, B.M., Munster, B.C. van, Korevaar, J.C., Haan, R.J. de, Rooij, S.E. de. Variability in measuring (instrumental) activities of daily living functioning and functional decline in hospitalized older medical patients: a systematic review. Journal of Clinical Epidemiology: 2011, 64(6), 619-627

Table 4

Variability of items within Katz ADL

\begin{tabular}{|c|c|c|c|c|c|c|c|c|c|c|c|}
\hline \multirow[b]{2}{*}{ Study } & \multirow[b]{3}{*}{ First author } & \multirow[b]{3}{*}{ Measure } & \multicolumn{6}{|c|}{ ADL items } & \multicolumn{3}{|c|}{ Mobility } \\
\hline & & & & & & & & & & & \\
\hline no & & & Bathing & Dressing & Toileting & Eating & Continence & Grooming & Transfer & Walking & Stairs \\
\hline 1 & Corsonello $^{19}$ & Katz ADL & $x$ & $x$ & $\mathrm{x}$ & $x$ & $x$ & & $x$ & $x$ & \\
\hline 2 & Leff $^{12}$ & Katz ADL & $x$ & $x$ & $x$ & $x$ & & & $x$ & & \\
\hline 3 & Inouye ${ }^{23}$ & Katz ADL & $x$ & $x$ & $x$ & $x$ & & $x$ & & & \\
\hline 4 & Brown ${ }^{15}$ & Katz ADL & $x$ & $x$ & $x$ & $\mathrm{x}$ & & $x$ & & & \\
\hline 5 & Murray ${ }^{29}$ & Katz ADL & $x$ & $x$ & $x$ & $x$ & & $x$ & $x$ & $x$ & \\
\hline 6 & Chaudry $^{17}$ & Katz ADL & $x$ & $x$ & $x$ & $x$ & & $x$ & $x$ & $x$ & \\
\hline 7 & Sager ${ }^{31}$ & Katz ADL & $\mathrm{x}$ & $x$ & $x$ & $x$ & & & $\mathrm{x}$ & $x$ & \\
\hline 8 & Inouye ${ }^{24}$ & Katz ADL & $x$ & $\mathrm{x}$ & $x$ & $x$ & & $x$ & & & \\
\hline 9 & Cornette $^{18}$ & Katz ADL & $x$ & $\mathrm{x}$ & $x$ & $x$ & $x$ & & & $x$ & \\
\hline 10 & Maraldi $^{28}$ & Katz ADL & $\mathrm{x}$ & $x$ & $x$ & $x$ & & $\mathrm{x}$ & $x$ & & \\
\hline 11 & Landefeld $^{10}$ & Katz ADL & $x$ & $\mathrm{x}$ & $x$ & $x$ & & & $x$ & & \\
\hline 12 & Inouye ${ }^{25}$ & Katz ADL & $\mathrm{x}$ & $x$ & $x$ & $x$ & $x$ & & $x$ & & \\
\hline 13 & Counsell $^{9}$ & Katz ADL & $x$ & $x$ & $x$ & $x$ & & & $\mathrm{x}$ & & \\
\hline 14 & Covinsky ${ }^{20}$ & Katz ADL & $x$ & $x$ & $x$ & $x$ & & & $x$ & & \\
\hline 15 & Lindenberger $^{21}$ & Katz ADL & $\mathrm{x}$ & $\mathrm{x}$ & $\mathrm{x}$ & $\mathrm{x}$ & & & $x$ & & \\
\hline 16 & Holroyd-leduc $^{22}$ & Katz ADL & $x$ & $x$ & $x$ & $\mathrm{x}$ & & & $x$ & & \\
\hline 17 & Lang $^{26}$ & Katz ADL & $x$ & $x$ & $x$ & $x$ & & & $x$ & & \\
\hline 18 & Boyd $^{14}$ & Katz ADL & $\mathrm{x}$ & $x$ & $x$ & $x$ & & & $x$ & & \\
\hline 19 & Sands ${ }^{32}$ & Katz ADL & $x$ & $x$ & $x$ & $x$ & & & $x$ & $x$ & $x$ \\
\hline 20 & Sager ${ }^{30}$ & Katz ADL & $\mathrm{x}$ & $x$ & $x$ & $x$ & & & $x$ & $x$ & \\
\hline 21 & Sands ${ }^{33}$ & Katz ADL & $x$ & $\mathrm{x}$ & $x$ & $\mathrm{x}$ & & & $x$ & & \\
\hline \multirow[t]{2}{*}{22} & Mahoney ${ }^{11}$ & Katz ADL & $x$ & $x$ & $x$ & $x$ & & & $x$ & & \\
\hline & \multicolumn{2}{|c|}{$\begin{array}{l}\% \text { of studies measuring } \\
\text { this item }\end{array}$} & 100 & 100 & 100 & 100 & 14 & 27 & 82 & 32 & 5 \\
\hline
\end{tabular}

Abbreviation: ADL, activities of daily living. 